\title{
Association Between Sleep Duration and Ideal Cardiovascular Health Among US Adults, National Health and Nutrition Examination Survey, 2013-2016
}

\author{
Rebecca E. Cash, PhD, MPH ${ }^{1,2,3}$; Chloe M. Beverly Hery, MS $^{1}$; \\ Ashish R. Panchal, MD, PhD ${ }^{1,2,4}$; Julie K. Bower, PhD, MPH ${ }^{1}$
}

\begin{abstract}
Accessible Version: www.cdc.gov/pcd/issues/2020/19_0424.htm
Suggested citation for this article: Cash RE, Beverly Hery CM, Panchal AR, Bower JK. Association Between Sleep Duration and Ideal Cardiovascular Health Among US Adults, National Health and Nutrition Examination Survey, 2013-2016. Prev Chronic Dis 2020;17:190424. DOI: https://doi.org/10.5888/pcd17.190424.
\end{abstract}

\section{PEER REVIEWED}

\section{Summary}

What is already known on this topic?

Short and long sleep durations are risk factors for cardiovascular disease, but limited work has assessed the association between sleep duration and cardiovascular health, a measure of the health of the cardiovascular system. Ideal cardiovascular health is associated with a reduced risk of developing cardiovascular disease.

\section{What is added by this report?}

By using a nationally representative sample of US adults from the National Health and Nutrition Examination Survey, we showed that very short $(<6$ h) and very long ( $\geq 9 \mathrm{~h}$ ) sleep duration was significantly associated with decreased odds of ideal cardiovascular health and a significant decrease in mean cardiovascular health score.

\section{What are the implications for public health practice?}

Sleep may be an additional component to describe health of the cardiovascular system. Unhealthy sleep duration represents a modifiable risk factor that can be targeted for population-level intervention.

\section{Abstract}

\section{Introduction}

Short or long sleep duration is a risk factor for cardiovascular disease, but the association between sleep duration and cardiovascular health is unclear. Our objective was to quantify the association between sleep duration and ideal cardiovascular health $(\mathrm{CVH})$ in
US adults. We hypothesized that very short $(<6 \mathrm{~h})$ and very long $(\geq 9 \mathrm{~h}$ ) sleep duration were associated with poorer $\mathrm{CVH}$ compared with sleep lasting 7 to $<8$ hours.

\section{Methods}

We conducted a cross-sectional evaluation of the nationally representative National Health and Nutrition Examination Survey in 2 cycles (2013-2014 and 2015-2016). Participants were 7,784 cardiovascular disease-free US adults aged 20 to 75. Self-reported sleep duration was categorized as $<6$ hours, 6 to $<7$ hours, 7 to $<8$ hours, 8 to $<9$ hours, and $\geq 9$ hours. The American Heart Association's ideal $\mathrm{CVH}$ metrics were used to determine the number of ideal CVH components, dichotomized as ideal (5-7 components) or not ideal (0-4 components). Survey-weighted logistic and linear regression models were used to determine the association between sleep duration and ideal $\mathrm{CVH}$.

\section{Results}

The weighted prevalences of those who slept 7 to $<8$ hours were $30.4 \%$, very short sleep duration $(<6 \mathrm{~h}), 9.0 \%$, and very long duration ( $\geq 9 \mathrm{~h}$ ), $13.5 \%$. Only $21.3 \%$ of the population had ideal CVH. Compared with 7 to $<8$ hours, very short duration $(\mathrm{OR}=0.65$; $95 \%$ confidence interval [CI], 0.47-0.90) and very long duration $(\mathrm{OR}=0.72 ; 95 \% \mathrm{CI}, 0.55-0.94)$ were associated with decreased odds of ideal CVH. We confirmed findings by using linear regression.

\section{Conclusions}

Very short and very long sleep duration were associated with decreased odds of ideal CVH and lower mean CVH scores. Future research should focus on clarifying causal associations between sleep duration and ideal $\mathrm{CVH}$. 


\section{Introduction}

Approximately $60 \%$ of US adults report sleeping the recommended 7 to 9 hours per night $(1,2)$. The consequences of unhealthy sleep, which include risk of chronic diseases, productivity loss, and fatigue-related performance concerns, have been described as a critical public health problem (3). Meta-analyses show a Ushaped association between short and long sleep duration and risk of developing cardiovascular disease (CVD) (4-6). Potential mechanisms for this association with short sleep include dysregulation of appetite hormones (7), glucose intolerance (4), the upand-down regulation of gene expression (8), and circadian rhythm misalignment (9), which may result in inflammatory conditions and development of other CVD risk factors such as hypertension $(10,11)$. The biologic mechanism of increased risk from long sleep is less clear and may be related to sleep fragmentation, depression, or underlying poor health (12).

Little evidence exists regarding the association between healthy sleep and a widely used metric for the general state of well-being of the cardiovascular system called ideal cardiovascular health (CVH). In 2010, the American Heart Association (AHA) defined ideal $\mathrm{CVH}$ on the basis of 7 modifiable factors: smoking, body mass index (BMI) (weight in $\mathrm{kg}$ divided by height in $\mathrm{m}^{2}$ ), diet, physical activity, blood pressure, fasting blood glucose, and total cholesterol (13). Each CVH component is scored as ideal, intermediate, or poor on the basis of established cut points (13). Meeting the ideal criteria for 5 to 7 components is associated with a reduced risk of developing CVD $(14,15)$.

Sleep debt is associated with poor CVH (16), and very short sleep duration is associated with increased odds of CVD risk factors such as hypertension and obesity (17). Because the association between ideal CVH and sleep duration remains unclear, our objective was to quantify that association among a nationally representative sample of US adults. We hypothesized that very short $(<6$ h) and very long ( $\geq 9 \mathrm{~h}$ ) sleep duration were associated with decreased odds of ideal CVH.

\section{Methods}

\section{Data source, sample, and design}

We conducted a cross-sectional analysis of data from the National Health and Nutrition Examination Survey (NHANES), a nationally representative cross-sectional survey of noninstitutionalized civilian residents of the United States, conducted continuously in 2 -year cycles (18). NHANES uses a complex sampling strategy with a multistage stratified probability cluster design to achieve a nationally representative sample. The survey consists of in-home interviews and a medical examination of approximately 10,000 children and adults at each 2-year cycle. The medical examination component is voluntarily completed by a subset of all participants. We used 2 cycles of NHANES for our evaluation, data collected in 2013-2014 and 2015-2016. These de-identified data are publicly available.

A total of 10,068 adults aged 20 to 75 completed the medical examination component during the 2 cycles. Of those, 7,784 (77\%) adults without a self-reported history of CVD (congestive heart failure, coronary heart disease, angina pectoris, myocardial infarction, or stroke), who had complete measurement of all cardiovascular health components and covariates were included in the analysis. A total of 834 respondents were excluded because of a history of CVD, 863 because they were missing CVH components, and 1,448 because they were missing covariates. Respondents could be excluded for more than 1 reason. The most common missing covariates were depression status $(n=590)$ and household income $(\mathrm{n}=521)$.

\section{Measures}

Exposure: sleep duration. Usual weekday or workday sleep duration was self-reported by participants. In 2013-2014, this information was elicited directly by asking for the usual hours of sleep on weekdays or workdays. In the 2015-2016 cycle, usual hours of sleep were calculated by asking respondents their normal bed time and wake time on weekdays or workdays. Sleep duration was categorized as $<6$ hours, 6 to $<7$ hours, 7 to $<8$ hours, 8 to $<9$ hours, and $\geq 9$ hours.

Outcome: cardiovascular health score. Cardiovascular health was defined according to the AHA's ideal CVH metrics (13). These metrics consist of 7 modifiable health behaviors and factors that were scored as ideal ( 2 points), intermediate ( 1 point), or poor ( 0 points) for adults, as described previously. Participants selfreported their smoking status, frequency of physical activity, and use of medications to control blood pressure, cholesterol, or diabetes mellitus. Dietary habits were reported through one or two 24-hour recalls (single day or average intake across both recalls). Ideal diet was assessed with the AHA Healthy Diet Score (13) by measuring the intake of fruits and vegetables, whole grains, sodium, fish, and sugar-sweetened beverages. Total cholesterol, hemoglobin $\mathrm{A}_{1 \mathrm{c}}$, and blood pressure were measured by trained professionals as part of the NHANES medical examination component. Hemoglobin $\mathrm{A}_{1 \mathrm{c}}$ was used as a proxy for fasting plasma glucose $(19,20)$; otherwise, we used the established CVH criteria (13). Briefly, the ideal criteria were never smoking or quit smoking more than 12 months ago; BMI of $<25.0 \mathrm{~kg} / \mathrm{m}^{2}$; meeting 4 to $5 \mathrm{of}$ the AHA Healthy Diet Score components; physical activity of $\geq 150$ minutes per week of moderate exercise, $\geq 75$ minutes per week of vigorous exercise, or $\geq 150$ minutes per week of moderate

The opinions expressed by authors contributing to this journal do not necessarily reflect the opinions of the U.S. Department of Health and Human Services, the Public Health Service, the Centers for Disease Control and Prevention, or the authors' affiliated institutions. 
and vigorous exercise; blood pressure of $<120 \mathrm{~mm} \mathrm{Hg} /<80 \mathrm{~mm}$ $\mathrm{Hg}$ without medication; total cholesterol of $<200 \mathrm{mg} / \mathrm{dl}$ without medication; and hemoglobin $\mathrm{A}_{1 \mathrm{c}}$ of $<5.7 \%$ without medication. The total score and number of ideal categories met by each participant were summed, and the resulting CVH score was analyzed as both continuous and categorical. For our study, overall ideal CVH was defined as meeting ideal criteria for 5 to 7 components, intermediate $\mathrm{CVH}$ as 3 to 4 components, and poor overall $\mathrm{CVH}$ as meeting 0 to 2 components. For logistic regression models, we further dichotomized the overall CVH score to ideal (5-7 categories) or not ideal ( $0-4$ categories).

Covariates. Covariates were selected a priori based on prior literature and substantive reasoning. Participant age, sex, race/ethnicity, education level, and marital status were self-reported. The ratio of monthly family income to poverty was used as a measure of socioeconomic status, categorized as $\leq 1.30,>1.30$ to $\leq 1.85$, and $>1.85$. This measure equates to the percentage above or below the federal poverty guidelines. Depression status was measured by the 9-item Patient Health Questionnaire depression screening instrument (21). The questionnaire scores items on a behavioral frequency scale and then dichotomizes them to none or moderate depression (0-14 points) and moderately severe to severe depression (15-27 points). Binge alcohol use was defined as drinking $\geq 4$ alcoholic drinks per day for women or $\geq 5$ for men, 12 or more times a year. Use of prescription sleep aids was self-reported. Reported current use of any of the following medications was considered use of sleep aid, regardless of frequency: amitriptyline, butabarbital, chloral hydrate, doxepin, estazolam, eszopiclone, flurazepam, mirtazapine, quazepam, ramelteon, temazepam, trazodone, triazolam, zaleplon, and zolpidem (22). Nonprescription sleep aid use was not documented.

\section{Statistical analyses}

For population level estimates, a 4-year sample weight was calculated by dividing in half the mobile examination center's sample analytic weights for the 2 cycles. Descriptive statistics were calculated, accounting for the complex survey design. We calculated unweighted frequency and weighted estimated population proportions or means. We also calculated the weighted population prevalence of each component and mean where appropriate and made comparisons by using Pearson's $\chi^{2}$ statistic or the Wald test that adjusted for the survey design. Available cases were used as a sensitivity analysis and compared with estimates from the complete cases. Survey-weighted multivariable logistic regression and linear regression were used to estimate the association between sleep duration and ideal CVH, controlling for covariates. Separate models were constructed controlling for demographic characterist- ics (age, sex, race, race/ethnicity, education level, family incometo-poverty ratio) and social/clinical factors (depression status, alcohol use, prescription sleep aid use). A final fully adjusted model included all covariates. All analyses were conducted in STATA IC 15.1 (StataCorp LLC) at the $\alpha=0.05$ level.

\section{Results}

The weighted mean age of the 7,784 participants included in our analysis was 44.5 (95\% confidence interval [CI], 43.8-45.2) (Table 1). Approximately half of participants were women $(51.5 \%$; 95\% CI, 50.3\%-52.7\%), and two-thirds were of non-Hispanic white race/ethnicity $(65.5 \%$; 95\% CI, 59.9\%-70.6\%). About twothirds $(64.0 \% ; 95 \% \mathrm{CI}, 60.2 \%-67.6 \%)$ had monthly family incomes that were greater than $185 \%$ of the federal poverty guidelines. The weighted prevalence of moderately severe or severe depression was $2.6 \%$ (95\% CI, 2.2\%-3.1\%), whereas $17.8 \%(95 \% \mathrm{CI}, 16.1 \%-19.5 \%)$ reported binge drinking once a month or more. The weighted prevalence of prescription sleep aid use was $4.3 \%(95 \% \mathrm{CI}, 3.5 \%-5.2 \%)$.

The weighted prevalence of those who slept 7 to $<8$ hours was $30.4 \%$ (95\% CI, 28.9\%-31.9\%), and the weighted prevalence of very short sleep ( $<6 \mathrm{~h})$ was $9.0 \%(95 \% \mathrm{CI}, 8.2 \%-9.9 \%)$ and very long ( $\geq 9$ h) sleep was $13.5 \%$ (95\% CI, 12.3\%-14.7\%). Ideal CVH was reported by only $17.8 \%$ (95\% CI, $16.3 \%-19.4 \%)$ of the population, and nearly half were classified as intermediate overall $\mathrm{CVH}$ (Table 1). Differences were significant in the weighted prevalence of the overall CVH score and in several of the CVH components when stratified by the reported sleep duration (Table 2). The proportion of respondents who met the ideal criteria was highest with sleep durations of 7 to $<9$ hours for smoking, physical activity, and hemoglobin $\mathrm{A}_{1 \mathrm{c}}$. Results were not materially different using available case analysis.

In the multivariable logistic regression models, we found a consistent association between very short sleep duration and decreased odds of ideal CVH (Table 3). In the unadjusted model, those with very short sleep duration had 0.53 times the odds of ideal CVH (95\% CI, 0.39-0.72) as those who slept 7 to $<8$ hours. We also saw an association between very long sleep duration and decreased odds of ideal CVH $(0.75$; 95\% CI, 0.58-0.98). We found no consistent association with ideal CVH for the other sleep durations. After adjusting the models for demographic factors and then social and clinical factors, similar associations were found. In the fully adjusted model, the effect was slightly attenuated but still significant with an adjusted odds ratio (OR) of 0.65 (95\% CI, $0.47-0.90)$. The association between very long sleep duration and ideal CVH remained similar with an adjusted OR of 0.72 (95\% CI, $0.55-0.94)$.

The opinions expressed by authors contributing to this journal do not necessarily reflect the opinions of the U.S. Department of Health and Human Services, the Public Health Service, the Centers for Disease Control and Prevention, or the authors' affiliated institutions. 
When examining the CVH score as a continuous variable, findings in the unadjusted and adjusted models were similar. In the fully adjusted model, a significant decrease was observed in the mean CVH score for participants with very short $(-0.41 ; 95 \% \mathrm{CI}$, -0.61 to -0.20$)$ and very long $(-0.33 ; 95 \% \mathrm{CI},-0.57$ to -0.09$)$ sleep durations, compared with those with sleep duration of 7 to $<9$ hours. Additionally, short sleep duration ( 6 to $<7$ hours) was also associated with a significant decrease in mean CVH score; no significant association was found for those with sleep duration of 8 to $<9$ hours.

\section{Discussion}

Ours is the first description to our knowledge of an association between sleep duration and ideal $\mathrm{CVH}$ that used a nationally representative sample of US adults. In this cross-sectional evaluation, very short sleep of $<6$ hours and very long sleep of $\geq 9$ hours were associated with decreased odds of ideal CVH and a significant decrease in mean CVH score after adjusting for demographic, clinical, and social factors. Because ideal $\mathrm{CVH}$ is related to the future risk of CVD, these findings provide evidence of associations between sleep duration and ideal $\mathrm{CVH}$ that require further investigation, including exploring causal associations that we were unable to assess in this cross-sectional study.

The overall prevalence of ideal $\mathrm{CVH}$ in this population is similar to past descriptions of adults. Globally, the prevalence of ideal CVH status overall is approximately $20 \%$ with estimates of between $15 \%$ and $20 \%$ for North American adults (23), which is similar to what we observed in our study. The proportion of US adults in our study sleeping 7 to $<9$ hours per night is consistent with prior estimates. Data from the Behavioral Risk Factor Surveillance System and the National Health Interview Survey estimated that about $60 \%$ of adults reported a sleep duration of this length $(2,24)$, consistent with the estimated $59.6 \%$ of adults in our study.

Data on the association between sleep duration and ideal CVH is scarce, though some work has been done looking at sleep debt, sleep quality, and daytime sleepiness. In a sample of older women (mean age 72 years), sleep debt was associated with poor $\mathrm{CVH}$, even after accounting for potentially confounding demographic and socioeconomic factors (16). Poor sleep quality in a population of Ecuadoran adults, as measured by the Pittsburgh Sleep Quality Index (25), was associated with some components of the $\mathrm{CVH}$ metrics but was not associated with poor CVH status overall (26). In that same population, excessive daytime sleepiness was also not associated with poor CVH status (27). This is in contrast to sub- stantial evidence of an association between incident cardiovascular disease and short sleep duration and, to a lesser extent, long sleep duration $(5,6)$.

The relationship between sleep and CVH likely differs from the association between sleep and CVD previously described. The etiology behind the differences is unclear but may be related to a bidirectional association between sleep patterns and a person's $\mathrm{CVH}$ metrics. The biologic mechanism for the effect of sleep duration on $\mathrm{CVH}$ has multiple pathways. Sleep duration is independently associated with several CVH metrics, such as weight status and hypertension, and with insulin sensitivity, which can lead to type 2 diabetes $(5,6,28)$. Poor sleep may also lead to changes in behavioral components such as increased frequency of smoking or decreased physical activity (29). It is still unclear, however, whether less than ideal health in these components may also affect sleep duration in the reverse manner. Also unclear is whether ideal $\mathrm{CVH}$ can lead to better sleep quality.

We found evidence of associations between both very short and very long sleep duration and decreased odds of ideal CVH and a significant decrease in mean $\mathrm{CVH}$ score. Although the U-shaped association between sleep duration and CVD has been increasingly described (4-6,30), some studies have shown that long sleep duration is protective for CVD or found nonsignificant associations (30). The biologic mechanism of long sleep duration and CVD or CVH is not as well understood as the mechanism of short sleep duration, especially because observed associations with long sleep durations may be related to reverse causality (eg, a result of CVD) or subclinical disease (30). We did adjust for some possible explanatory factors such as depression and use of prescription sleep aids, but the potential for residual confounding or other bias may have affected the results in this study.

Our study had several strengths, including the large sample size and use of the nationally representative NHANES population. However, our study had limitations. Although the sample size was large enough to detect significant differences, we excluded a proportion of participants $(1,468$ of 9,252 [16\%] eligible adults without prevalent CVD) because of missing data who otherwise would have been eligible for inclusion. However, when comparing all participants with available data to the analytic sample, we found no substantial differences. Sleep duration was assessed by self-report and included only assessment of weekday or workday sleep. In past studies, participant self-reported sleep durations were overestimated compared with objectively measured durations, especially by those with the shortest sleep durations (31). Thus, misclassification is possible, though the direction of bias is likely toward the null because participants tended to overestimate instead of underestimate sleep. Additionally, several of the $\mathrm{CVH}$ metrics were also self-reported, including smoking status, physic-

\footnotetext{
The opinions expressed by authors contributing to this journal do not necessarily reflect the opinions of the U.S. Department of Health and Human Services, the Public Health Service, the Centers for Disease Control and Prevention, or the authors' affiliated institutions.
} 
al activity, and dietary habits. The other components of the CVH metrics, however, were measured in a standardized manner with trained assessors as part of the NHANES data collection process. The cross-sectional study design does not allow for inferring causality between sleep duration and ideal CVH status. Finally, we could not account for other confounders such as sleep apnea and use of nonprescription sleep aids in our analysis.

Our study demonstrated an association between very short and very long sleep duration and reduced $\mathrm{CVH}$, as suggested by decreased odds of ideal $\mathrm{CVH}$ and a decrease in mean CVH score. More work is needed to understand the implications of sleep duration and the metrics of $\mathrm{CVH}$, including potential causal associations.

\section{Acknowledgments}

Author contributions were R.E.C., conceptualization, methodology, formal analysis, and writing of the original draft; C.M.B.H., conceptualization, methodology, writing, review, and editing; A.R.P., writing, review, and editing; and J.K.B., conceptualization, supervision, writing, review, and editing. No financial support was received for this work, and no copyrighted material was used in the article. The authors have no conflicts to disclose.

\section{Author Information}

Corresponding Author: Rebecca E. Cash, PhD, MPH, Department of Emergency Medicine, Massachusetts General Hospital, 125 Nashua St, Ste 920, Boston, MA 02114. Telephone: 617-7268847. Email: rcash@mgh.harvard.edu.

Author Affiliations: ${ }^{1}$ The Ohio State University College of Public Health, Division of Epidemiology, Columbus, Ohio. ${ }^{2}$ National Registry of Emergency Medical Technicians, Columbus, Ohio. ${ }^{3}$ Massachusetts General Hospital, Department of Emergency Medicine, Boston, Massachusetts. ${ }^{4}$ The Ohio State University Wexner Medical Center, Department of Emergency Medicine, Columbus, Ohio.

\section{References}

1. Hirshkowitz M, Whiton K, Albert SM, Alessi C, Bruni O, DonCarlos L, et al. National Sleep Foundation's updated sleep duration recommendations: final report. Sleep Health 2015; 1(4):233-43.

2. Liu Y, Wheaton AG, Chapman DP, Cunningham TJ, Lu H, Croft JB. Prevalence of healthy sleep duration among adults United States, 2014. MMWR Morb Mortal Wkly Rep 2016; 65(6): $137-41$.
3. Extent and health consequences of chronic sleep loss and sleep disorders. In: Institute of Medicine (US) Committee on Sleep Medicine and Research, Colten HR, Altevogt BM, editors. Sleep disorders and sleep deprivation: an unmet public health problem. Washington (DC): National Academies Press; 2006.

4. Cappuccio FP, Cooper D, D'Elia L, Strazzullo P, Miller MA. Sleep duration predicts cardiovascular outcomes: a systematic review and meta-analysis of prospective studies. Eur Heart J 2011;32(12):1484-92.

5. Itani O, Jike M, Watanabe N, Kaneita Y. Short sleep duration and health outcomes: a systematic review, meta-analysis, and meta-regression. Sleep Med 2017;32:246-56.

6. Jike M, Itani O, Watanabe N, Buysse DJ, Kaneita Y. Long sleep duration and health outcomes: a systematic review, metaanalysis and meta-regression. Sleep Med Rev 2018;39:25-36.

7. Spiegel K, Tasali E, Leproult R, Van Cauter E. Effects of poor and short sleep on glucose metabolism and obesity risk. Nat Rev Endocrinol 2009;5(5):253-61.

8. Möller-Levet CS, Archer SN, Bucca G, Laing EE, Slak A, Kabiljo R, et al. Effects of insufficient sleep on circadian rhythmicity and expression amplitude of the human blood transcriptome. Proc Natl Acad Sci USA 2013 ; 110(12):E1132-41.

9. Pavlova M. Circadian rhythm sleep-wake disorders. Continuum (Minneap Minn) 2017;23(4, Sleep Neurology):1051-63.

10. Covassin N, Singh P. Sleep duration and cardiovascular disease risk: epidemiologic and experimental evidence. Sleep Med Clin 2016;11(1):81-9.

11. Machado RM, Koike MK. Circadian rhythm, sleep pattern, and metabolic consequences: an overview on cardiovascular risk factors. Horm Mol Biol Clin Investig 2014;18(1):47-52.

12. Grandner MA, Drummond SP. Who are the long sleepers? Towards an understanding of the mortality relationship. Sleep Med Rev 2007;11(5):341-60.

13. Lloyd-Jones DM, Hong Y, Labarthe D, Mozaffarian D, Appel LJ, Van Horn L, et al.; American Heart Association Strategic Planning Task Force and Statistics Committee. Defining and setting national goals for cardiovascular health promotion and disease reduction: the American Heart Association's strategic Impact Goal through 2020 and beyond. Circulation 2010; 121(4):586-613.

14. Ommerborn MJ, Blackshear CT, Hickson DA, Griswold ME, Kwatra J, Djoussé L, et al. Ideal cardiovascular health and incident cardiovascular events: the Jackson Heart Study. Am J Prev Med 2016;51(4):502-6.

The opinions expressed by authors contributing to this journal do not necessarily reflect the opinions of the U.S. Department of Health and Human Services, the Public Health Service, the Centers for Disease Control and Prevention, or the authors' affiliated institutions. 
15. Ramírez-Vélez R, Saavedra JM, Lobelo F, Celis-Morales CA, Pozo-Cruz BD, García-Hermoso A. Ideal cardiovascular health and incident cardiovascular disease among adults: a systematic review and meta-analysis. Mayo Clin Proc 2018; 93(11):1589-99.

16. Cabeza de Baca T, Chayama KL, Redline S, Slopen N, Matsushita F, Prather AA, et al. Sleep debt: the impact of weekday sleep deprivation on cardiovascular health in older women. Sleep (Basel) 2019;42(10):zsz149.

17. Grandner MA, Chakravorty S, Perlis ML, Oliver L, Gurubhagavatula I. Habitual sleep duration associated with self-reported and objectively determined cardiometabolic risk factors. Sleep Med 2014;15(1):42-50.

18. Centers for Disease Control and Prevention, National Center for Health Statistics. National Health and Nutrition Examination Survey. https://wwwn.cdc.gov/nchs/nhanes/. Accessed January 25, 2020

19. American Diabetes Association. 2. Classification and Diagnosis of Diabetes: Standards of Medical Care in Diabetes - 2018. Diabetes Care 2018;41(Suppl 1):S13-27.

20. García-Hermoso A, Martínez-Vizcaíno V, Gomez-Marcos MA, Cavero-Redondo I, Recio-Rodriguez JI, García-Ortiz L. Ideal cardiovascular health and arterial stiffness in Spanish adults - the EVIDENT Study. J Stroke Cerebrovasc Dis 2018;27(5):1386-94.

21. Kroenke K, Spitzer RL, Williams JB. The PHQ-9: validity of a brief depression severity measure. J Gen Intern Med 2001; 16(9):606-13.

22. Chong Y, Fryer CD, Gu Q. Prescription sleep aid use among adults: United States, 2005-2010. NCHS Data Brief 2013; (127):1-8.

23. Peng Y, Cao S, Yao Z, Wang Z. Prevalence of the cardiovascular health status in adults: a systematic review and meta-analysis. Nutr Metab Cardiovasc Dis 2018 ; 28(12):1197-207.

24. Ford ES, Cunningham TJ, Croft JB. Trends in self-reported sleep duration among US adults from 1985 to 2012. Sleep (Basel) 2015;38(5):829-32.

25. Buysse DJ, Reynolds CF 3d, Monk TH, Berman SR, Kupfer DJ. The Pittsburgh Sleep Quality Index: a new instrument for psychiatric practice and research. Psychiatry Res 1989; 28(2):193-213.

26. Del Brutto OH, Mera RM, Zambrano M, Del Brutto VJ, Castillo PR. Association between sleep quality and cardiovascular health: a door-to-door survey in rural Ecuador. Environ Health Prev Med 2014;19(3):234-7.

27. Del Brutto OH, Mera RM, Zambrano M, Castillo PR. Excessive daytime somnolence and cardiovascular health: a population-based study in rural Ecuador. Sleep Sci 2014; 7(4):186-8.
28. Spaeth AM, Dinges DF, Goel N. Effects of experimental sleep restriction on weight gain, caloric intake, and meal timing in healthy adults. Sleep (Basel) 2013;36(7):981-90.

29. Patterson F, Grandner MA, Lozano A, Satti A, Ma G. Transitioning from adequate to inadequate sleep duration associated with higher smoking rate and greater nicotine dependence in a population sample. Addict Behav 2018; 77:47-50.

30. Yin J, Jin X, Shan Z, Li S, Huang H, Li P, et al. Relationship of sleep duration with all-cause mortality and cardiovascular events: a systematic review and dose-response meta-analysis of prospective cohort studies. J Am Heart Assoc 2017; 6(9):e005947.

31. Lauderdale DS, Knutson KL, Yan LL, Liu K, Rathouz PJ. Self-reported and measured sleep duration: how similar are they? Epidemiology 2008;19(6):838-45.

\footnotetext{
The opinions expressed by authors contributing to this journal do not necessarily reflect the opinions of the U.S. Department of Health and Human Services, the Public Health Service, the Centers for Disease Control and Prevention, or the authors' affiliated institutions.
} 


\section{Tables}

Table 1. Estimated Weighted Population Characteristics and Prevalence of Sleep and Cardiovascular Health Among US Adults Aged 20-75 ( $\mathrm{N}=7,784$ ), National Health and Nutrition Examination Survey, 2013-2016

\begin{tabular}{|c|c|c|}
\hline Characteristic & Unweighted, No. & Weighted $^{a}$ \\
\hline Age, mean, $y$ & 7,784 & $44.5(43.8-45.2)$ \\
\hline \multicolumn{3}{|l|}{ Sex } \\
\hline Male & 3,704 & $48.5(47.3-49.7)$ \\
\hline Female & 4,080 & $51.5(50.3-52.7)$ \\
\hline \multicolumn{3}{|l|}{ Race/ethnicity } \\
\hline Non-Hispanic white & 2,882 & $65.5(59.9-70.6)$ \\
\hline Non-Hispanic black & 1,606 & $10.9(8.5-13.9)$ \\
\hline Hispanic & 2,111 & $15.2(11.7-19.4)$ \\
\hline Non-Hispanic other & 1,185 & $8.4(7.1-10.1)$ \\
\hline \multicolumn{3}{|l|}{ Education level } \\
\hline High school diploma or less & 3,247 & $33.4(30.1-36.9)$ \\
\hline Some college & 2,447 & $33.3(31.2-35.5)$ \\
\hline College graduate or above & 2,090 & $33.3(29.4-37.5)$ \\
\hline \multicolumn{3}{|l|}{ Marital status } \\
\hline Married or coupled & 4,760 & $64.9(62.7-67.0)$ \\
\hline Widowed, divorced, or separated & 1,387 & $15.3(13.9-16.7)$ \\
\hline Never married & 1,637 & $19.8(18.0-21.8)$ \\
\hline \multicolumn{3}{|l|}{ Family income-to-poverty ratio } \\
\hline$\leq 1.3$ & 2,755 & $24.4(21.4-27.6)$ \\
\hline$>1.3$ to $\leq 1.85$ & 1,082 & $11.7(10.5-13.0)$ \\
\hline$>1.85$ & 3,947 & $64.0(60.2-67.6)$ \\
\hline Moderately severe or severe depression & 235 & $2.6(2.2-3.1)$ \\
\hline Binge drinking once a month or more ${ }^{b}$ & 1,217 & $17.8(16.1-19.5)$ \\
\hline Prescription sleep aid use & 267 & $4.3(3.5-5.2)$ \\
\hline \multicolumn{3}{|l|}{ Sleep duration, $\mathrm{h}$} \\
\hline$<6$ & 862 & $9.0(8.2-9.9)$ \\
\hline 6 to $<7$ & 1,571 & $18.5(17.3-19.8)$ \\
\hline 7 to $<8$ & 2,135 & $30.4(28.9-31.9)$ \\
\hline 8 to $<9$ & 2,112 & $28.6(27.5-29.7)$ \\
\hline$\geq 9$ & 1,104 & $13.5(12.3-14.7)$ \\
\hline
\end{tabular}

Abbreviations: $\mathrm{Cl}$, confidence interval; $\mathrm{CVH}$, cardiovascular health.

${ }^{a}$ Values are percentage (95\% confidence interval) unless otherwise indicated. Because of survey weighting, proportions differ from calculations based on the unweighted number. Percentages may not total to $100 \%$ because of rounding.

${ }^{\mathrm{b}}$ Binge drinking was defined as more than 4 drinks per day for women or more than 5 drinks per day for men.

${ }^{\mathrm{c}}$ Mean score excluded those who were missing 1 or more $\mathrm{CVH}$ components. 
(continued)

Table 1. Estimated Weighted Population Characteristics and Prevalence of Sleep and Cardiovascular Health Among US Adults Aged 20-75 (N = 7,784), National Health and Nutrition Examination Survey, 2013-2016

\begin{tabular}{|c|c|c|}
\hline Characteristic & Unweighted, No. & Weighted $^{a}$ \\
\hline Mean & $6,985^{c}$ & $8.0(7.9-8.1)$ \\
\hline Ideal (5-7 components) & 1,156 & $17.8(16.3-19.4)$ \\
\hline Intermediate (3-4 components) & 2,947 & $42.1(40.9-43.3)$ \\
\hline Poor (0-2 components) & 3,200 & $40.1(38.4-41.9)$ \\
\hline
\end{tabular}

Abbreviations: $\mathrm{Cl}$, confidence interval; $\mathrm{CVH}$, cardiovascular health.

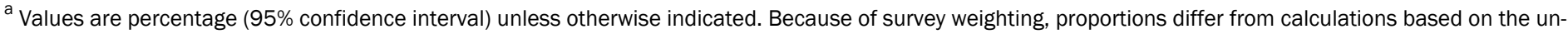
weighted number. Percentages may not total to $100 \%$ because of rounding.

${ }^{b}$ Binge drinking was defined as more than 4 drinks per day for women or more than 5 drinks per day for men.

${ }^{\mathrm{c}}$ Mean score excluded those who were missing 1 or more $\mathrm{CVH}$ components. 
Table 2. Weighted Mean and Population Prevalence of Overall CVH Score and Individual Components Stratified By Sleep Duration Among US Adults Aged 20-75 (N $=7,784$ ), National Health and Nutrition Examination Survey, 2013-2016

\begin{tabular}{|c|c|c|c|c|c|c|c|}
\hline \multirow[b]{2}{*}{ Component } & \multirow[b]{2}{*}{ Definition $^{a}$} & \multicolumn{5}{|c|}{ Weighted Sleep Duration, mean or \% $(95 \% \mathrm{Cl})$} & \multirow[b]{2}{*}{$P$ Value $^{\mathrm{b}}$} \\
\hline & & $<6 \mathrm{~h}$ & 6 to $<7 \mathrm{~h}$ & 7 to $<8 \mathrm{~h}$ & 8 to $<9 h$ & $\geq 9 \mathrm{~h}$ & \\
\hline \multicolumn{8}{|c|}{ Overall CVH score ${ }^{c}$} \\
\hline Mean & NA & $7.4(7.2-7.6)$ & $7.9(7.8-8.0)$ & $8.2(8.1-8.4)$ & $8.1(7.9-8.3)$ & $7.7(7.4-8.0)$ & $<.001$ \\
\hline Ideal & $5-7$ & $11.1(8.3-14.7)$ & $17.9(15.9-20.0)$ & $\begin{array}{r}19.1 \\
(17.1-21.3)\end{array}$ & $\begin{array}{r}20.1 \\
(17.8-22.6)\end{array}$ & $\begin{array}{r}15.5 \\
(12.7-18.7)\end{array}$ & \multirow{3}{*}{.01} \\
\hline Intermediate & $3-4$ & $\begin{array}{r}41.2 \\
(36.0-46.6)\end{array}$ & $41.5(38.5-44.7)$ & $\begin{array}{r}43.6 \\
(40.6-46.7)\end{array}$ & $\begin{array}{r}41.9 \\
(39.3-44.7)\end{array}$ & $\begin{array}{r}41.0 \\
(37.6-44.5)\end{array}$ & \\
\hline Poor & $0-2$ & $\begin{array}{r}47.8 \\
(43.0-52.6) \\
\end{array}$ & $40.6(37.9-43.3)$ & $\begin{array}{r}37.3 \\
(34.4-40.2)\end{array}$ & $\begin{array}{r}38.0 \\
(35.1-41.0) \\
\end{array}$ & $\begin{array}{r}43.6 \\
(39.4-47.8)\end{array}$ & \\
\hline \multicolumn{8}{|l|}{ Smoking } \\
\hline Ideal & Never smoker or quit $\geq 12$ months ago & $\begin{array}{r}47.9 \\
(41.7-54.2)\end{array}$ & $56.0(52.2-59.8)$ & $\begin{array}{r}63.2 \\
(60.5-65.7)\end{array}$ & $\begin{array}{r}60.3 \\
(57.1-63.4)\end{array}$ & $\begin{array}{r}57.0 \\
(52.5-61.4)\end{array}$ & \multirow{3}{*}{$<.001$} \\
\hline Intermediate & $\begin{array}{l}\text { Smoked } \geq 100 \text { cigarettes and quit }<12 \\
\text { months ago }\end{array}$ & $\begin{array}{r}21.6 \\
(17.7-25.9) \\
\end{array}$ & $21.6(18.8-24.8)$ & $\begin{array}{r}22.0 \\
(19.4-24.7) \\
\end{array}$ & $\begin{array}{r}23.7 \\
(21.3-26.2) \\
\end{array}$ & $\begin{array}{r}19.2 \\
(16.4-22.3)\end{array}$ & \\
\hline Poor & Current smoker & $\begin{array}{r}30.6 \\
(25.6-36.1)\end{array}$ & $22.4(19.4-25.7)$ & $\begin{array}{r}14.9 \\
(12.7-17.5)\end{array}$ & $\begin{array}{r}16.0 \\
(13.7-18.7)\end{array}$ & $\begin{array}{r}23.8 \\
(20.3-27.8)\end{array}$ & \\
\hline \multicolumn{8}{|c|}{ Body mass index (kg weight/height in $\mathrm{m}^{2}$ ) } \\
\hline Mean & NA & $\begin{array}{r}30.6 \\
(30.1-31.1) \\
\end{array}$ & $29.6(29.0-3.2)$ & $\begin{array}{r}29.1 \\
(28.6-29.5) \\
\end{array}$ & $\begin{array}{r}29.0 \\
(38.4-29.5) \\
\end{array}$ & $\begin{array}{r}29.0 \\
(28.4-29.7)\end{array}$ & $<.001$ \\
\hline Ideal & $<25.0 \mathrm{~kg} / \mathrm{m}^{2}$ & $\begin{array}{r}23.3 \\
(19.3-27.8) \\
\end{array}$ & $27.0(23.9-30.4)$ & $\begin{array}{r}30.1 \\
(27.6-32.8) \\
\end{array}$ & $\begin{array}{r}30.4 \\
(26.5-34.6) \\
\end{array}$ & $\begin{array}{r}31.2 \\
(27.3-35.3) \\
\end{array}$ & \multirow{3}{*}{.03} \\
\hline Intermediate & $25.0-29.9 \mathrm{~kg} / \mathrm{m}^{2}$ & $\begin{array}{r}30.1 \\
(26.0-34.7) \\
\end{array}$ & $32.6(29.6-35.7)$ & $\begin{array}{r}32.9 \\
(30.1-35.9) \\
\end{array}$ & $\begin{array}{r}32.7 \\
(30.2-35.3) \\
\end{array}$ & $\begin{array}{r}30.3 \\
(27.0-33.9) \\
\end{array}$ & \\
\hline Poor & $\geq 30.0 \mathrm{~kg} / \mathrm{m}^{2}$ & $\begin{array}{r}46.6 \\
(41.6-51.6)\end{array}$ & $40.4(37.0-43.8)$ & $\begin{array}{r}37.0 \\
(34.2-39.8)\end{array}$ & $\begin{array}{r}36.9 \\
(33.2-40.8)\end{array}$ & $\begin{array}{r}38.5 \\
(34.0-43.3)\end{array}$ & \\
\hline \multicolumn{8}{|l|}{$\operatorname{Diet}^{d}$} \\
\hline Ideal & 4-5 components & 0 & 0 & 0 & 0 & $0.1(0.0-0.6)$ & \multirow{3}{*}{.10} \\
\hline Intermediate & 2-3 components & $\begin{array}{r}22.3 \\
(17.2-28.3) \\
\end{array}$ & $24.4(21.2-28.0)$ & $\begin{array}{r}26.8 \\
(23.9-29.9) \\
\end{array}$ & $\begin{array}{r}25.7 \\
(22.7-28.9) \\
\end{array}$ & $\begin{array}{r}20.2 \\
(17.4-23.2) \\
\end{array}$ & \\
\hline Poor & $0-1$ components & $\begin{array}{r}77.7 \\
(71.7-82.8)\end{array}$ & $75.6(72.0-78.8)$ & $\begin{array}{r}73.2 \\
(70.1-76.1)\end{array}$ & $\begin{array}{r}74.3 \\
(71.1-77.3)\end{array}$ & $\begin{array}{r}79.7 \\
(76.6-82.5)\end{array}$ & \\
\hline \multicolumn{8}{|c|}{ Physical activity, min/wk } \\
\hline Mean & NA & $\begin{array}{r}168.9 \\
(144.0-193.7)\end{array}$ & $\begin{array}{r}165.9 \\
(150.8-180.9)\end{array}$ & $\begin{array}{r}165.6 \\
(147.2-184.0)\end{array}$ & $\begin{array}{r}171.8 \\
(154.1-189.5)\end{array}$ & $\begin{array}{r}166.6 \\
(136.0-197.2)\end{array}$ & .98 \\
\hline
\end{tabular}

Abbreviations: $\mathrm{Cl}$, confidence interval; $\mathrm{CVH}$, cardiovascular health; DBP, diastolic blood pressure; NA, not applicable; SBP, systolic blood pressure.

${ }^{a}$ Component definitions and scoring used were those previously described by Lloyd-Jones et al. with modification of hemoglobin $\mathrm{A}_{1 \mathrm{c}}$ as a proxy for fasting plasma glucose (13). The specific definitions used in this analysis are presented.

${ }^{b} P$ value calculated from adjusted Wald or Pearson's $x^{2}$ tests that were corrected for the survey design.

${ }^{\mathrm{C}}$ The CVH score comprises 7 components: smoking, body mass index, diet, physical activity, blood pressure, total cholesterol, and hemoglobin $\mathrm{A1c}$ (used as a proxy for fasting plasma glucose) (13). Each component was scored as ideal (2 points), intermediate (1 point), or poor (0 points) based on guidelines described by LloydJones et al (13). The continuous overall CVH score was calculated by summing the 7 components scores. Ideal CVH was defined as meeting ideal criteria for 5 to 7 of the components.

${ }^{d}$ American Heart Association Healthy Diet Score includes $\geq 4.5$ cups of fruits or vegetables a day; two 3.5-ounce servings of fish per week; $\geq 3$ one-ounce equivalent servings of whole grains per day; $<1,500 \mathrm{mg}$ of sodium per day; $\leq 36$ ounces of sugar-sweetened beverages per week. 
(continued)

Table 2. Weighted Mean and Population Prevalence of Overall CVH Score and Individual Components Stratified By Sleep Duration Among US Adults Aged 20-75 (N $=7,784$ ), National Health and Nutrition Examination Survey, 2013-2016

\begin{tabular}{|c|c|c|c|c|c|c|c|}
\hline \multirow[b]{2}{*}{ Component } & \multirow[b]{2}{*}{ Definition $^{a}$} & \multicolumn{5}{|c|}{ Weighted Sleep Duration, mean or \% $(95 \% \mathrm{Cl})$} & \multirow[b]{2}{*}{$P$ Value $^{\mathrm{b}}$} \\
\hline & & $<6 \mathrm{~h}$ & 6 to $<7 \mathrm{~h}$ & 7 to $<8 \mathrm{~h}$ & 8 to $<9 h$ & $\geq 9 \mathrm{~h}$ & \\
\hline Ideal & $\begin{array}{l}\geq 150 \text { min moderate and/or vigorous or } \\
\geq 75 \text { min vigorous }\end{array}$ & $\begin{array}{r}34.0 \\
(29.7-38.6)\end{array}$ & $39.1(35.8-42.5)$ & $\begin{array}{r}43.1 \\
(39.3-47.0)\end{array}$ & $\begin{array}{r}41.9 \\
(38.4-45.5)\end{array}$ & $\begin{array}{r}37.2 \\
(32.0-42.7)\end{array}$ & \multirow{3}{*}{.03} \\
\hline Intermediate & $\begin{array}{l}\text { 1-149 min moderate and/or vigorous or } \\
1-74 \text { min vigorous }\end{array}$ & $\begin{array}{r}17.1 \\
(14.3-20.3) \\
\end{array}$ & $16.7(13.9-20.0)$ & $\begin{array}{r}16.3 \\
(14.2-18.7) \\
\end{array}$ & $\begin{array}{r}19.2 \\
(17.0-21.7) \\
\end{array}$ & $\begin{array}{r}14.6 \\
(11.7-18.1) \\
\end{array}$ & \\
\hline Poor & None & $\begin{array}{r}49.0 \\
(45.3-52.7)\end{array}$ & $44.2(40.5-47.9)$ & $\begin{array}{r}40.6 \\
(37.5-43.8)\end{array}$ & $\begin{array}{r}38.9 \\
(35.3-42.6)\end{array}$ & $\begin{array}{r}48.2 \\
(42.9-53.6)\end{array}$ & \\
\hline \multicolumn{8}{|c|}{ Blood pressure, $\mathrm{mm} \mathrm{Hg}$} \\
\hline Systolic, mean & NA & $\begin{array}{r}122.3 \\
(120.7-123.8) \\
\end{array}$ & $\begin{array}{r}121.3 \\
(120.2-122.4)\end{array}$ & $\begin{array}{r}120.5 \\
(119.6-121.4)\end{array}$ & $\begin{array}{r}121.3 \\
(120.4-122.2)\end{array}$ & $\begin{array}{r}121.8 \\
(120.3-123.2)\end{array}$ & .25 \\
\hline Diastolic, mean & NA & $\begin{array}{r}71.9 \\
(70.8-73.1) \\
\end{array}$ & $70.9(70.1-71.7)$ & $\begin{array}{r}70.6 \\
(69.8-71.4) \\
\end{array}$ & $\begin{array}{r}70.5 \\
(69.6-71.3) \\
\end{array}$ & $\begin{array}{r}70.3 \\
(69.1-71.5) \\
\end{array}$ & .16 \\
\hline Ideal & $<120 /<80$ untreated & $\begin{array}{r}43.7 \\
(39.5-48.0) \\
\end{array}$ & $44.0(40.7-47.3)$ & $\begin{array}{r}47.1 \\
(43.6-50.6) \\
\end{array}$ & $\begin{array}{r}46.7 \\
(44.2-49.2) \\
\end{array}$ & $\begin{array}{r}42.0 \\
(38.3-45.8) \\
\end{array}$ & \multirow{3}{*}{.24} \\
\hline Intermediate & $\begin{array}{l}\text { SBP } 120-139 \text { or DBP } 80-89 \text { or treated } \\
\text { to goal }\end{array}$ & $\begin{array}{r}46.0 \\
(41.6-50.5) \\
\end{array}$ & $48.3(45.2-51.5)$ & $\begin{array}{r}45.5 \\
(42.1-49.0)\end{array}$ & $\begin{array}{r}45.0 \\
(42.7-47.2)\end{array}$ & $\begin{array}{r}48.1 \\
(43.4-52.8)\end{array}$ & \\
\hline Poor & $\mathrm{SBP} \geq 140$ or $\mathrm{DBP} \geq 90$ & $10.3(7.1-14.8)$ & $7.7(6.2-9.6)$ & $7.4(6.3-8.7)$ & $8.3(6.7-10.3)$ & $9.9(7.0-13.9)$ & \\
\hline \multicolumn{8}{|c|}{ Total cholesterol, mg/dl } \\
\hline Mean & NA & $\begin{array}{r}191.9 \\
(187.6-196.3) \\
\end{array}$ & $\begin{array}{r}189.6 \\
(186.6-192.7) \\
\end{array}$ & $\begin{array}{r}192.1 \\
(190.0-194.2) \\
\end{array}$ & $\begin{array}{r}195.4 \\
(192.1-198.7) \\
\end{array}$ & $\begin{array}{r}193.0 \\
(188.5-197.4) \\
\end{array}$ & .07 \\
\hline Ideal & $<200$ untreated & $\begin{array}{r}50.6 \\
(45.3-55.9) \\
\end{array}$ & $55.4(51.3-59.4)$ & $\begin{array}{r}50.1 \\
(46.9-53.3) \\
\end{array}$ & $\begin{array}{r}49.0 \\
(44.9-53.2) \\
\end{array}$ & $\begin{array}{r}48.6 \\
(44.7-52.5) \\
\end{array}$ & \multirow{3}{*}{.02} \\
\hline Intermediate & $200-239$ or treated to goal & $\begin{array}{r}39.3 \\
(34.5-44.4)\end{array}$ & $34.5(30.9-38.1)$ & $\begin{array}{r}38.5 \\
(35.1-42.1)\end{array}$ & $\begin{array}{r}36.2 \\
(33.0-39.5)\end{array}$ & $\begin{array}{r}36.7 \\
(32.3-41.3)\end{array}$ & \\
\hline Poor & $\geq 240$ & $10.1(8.3-12.4)$ & $10.2(8.2-12.5)$ & $11.4(9.5-13.5)$ & $\begin{array}{r}14.8 \\
(12.7-17.1)\end{array}$ & $\begin{array}{r}14.7 \\
(11.5-18.6)\end{array}$ & \\
\hline \multicolumn{8}{|c|}{ Hemoglobin $A_{1 c}, \%$} \\
\hline Mean & NA & $5.7(5.6-5.7)$ & $5.6(5.6-5.7)$ & $5.5(5.5-5.6)$ & $5.6(5.5-5.6)$ & $5.6(5.5-5.7)$ & .01 \\
\hline Ideal & $<5.7$ untreated & $\begin{array}{r}66.1 \\
(61.1-70.9) \\
\end{array}$ & $70.8(67.8-73.7)$ & $\begin{array}{r}74.3 \\
(71.6-76.8) \\
\end{array}$ & $\begin{array}{r}72.9 \\
(70.1-75.5) \\
\end{array}$ & $\begin{array}{r}65.8 \\
(59.7-71.4) \\
\end{array}$ & \multirow{3}{*}{.008} \\
\hline Intermediate & $5.7-6.4$ or treated to goal & $\begin{array}{r}30.2 \\
(25.5-35.3) \\
\end{array}$ & $26.0(23.1-29.1)$ & $\begin{array}{r}23.2 \\
(21.0-25.6) \\
\end{array}$ & $\begin{array}{r}24.5 \\
(22.2-26.9) \\
\end{array}$ & $\begin{array}{r}30.8 \\
(25.6-36.6) \\
\end{array}$ & \\
\hline Poor & $\geq 6.5$ & $3.7(2.5-5.4)$ & $3.2(2.4-4.4)$ & $2.5(1.7-3.7)$ & $2.6(1.9-3.5)$ & $3.4(2.3-4.9)$ & \\
\hline
\end{tabular}

Abbreviations: $\mathrm{Cl}$, confidence interval; $\mathrm{CVH}$, cardiovascular health; $\mathrm{DBP}$, diastolic blood pressure; NA, not applicable; SBP, systolic blood pressure.

${ }^{a}$ Component definitions and scoring used were those previously described by Lloyd-Jones et al. with modification of hemoglobin $\mathrm{A}_{1 \mathrm{c}}$ as a proxy for fasting plasma glucose (13). The specific definitions used in this analysis are presented.

${ }^{b} P$ value calculated from adjusted Wald or Pearson's $x^{2}$ tests that were corrected for the survey design.

${ }^{\mathrm{C}}$ The CVH score comprises 7 components: smoking, body mass index, diet, physical activity, blood pressure, total cholesterol, and hemoglobin ${ }_{\mathrm{A} 1 \mathrm{c}}$ (used as a proxy for fasting plasma glucose) (13). Each component was scored as ideal (2 points), intermediate (1 point), or poor (0 points) based on guidelines described by LloydJones et al (13). The continuous overall $\mathrm{CVH}$ score was calculated by summing the 7 components scores. Ideal CVH was defined as meeting ideal criteria for 5 to 7 of the components.

${ }^{d}$ American Heart Association Healthy Diet Score includes $\geq 4.5$ cups of fruits or vegetables a day; two 3.5-ounce servings of fish per week; $\geq 3$ one-ounce equivalent servings of whole grains per day; $<1,500 \mathrm{mg}$ of sodium per day; $\leq 36$ ounces of sugar-sweetened beverages per week.

The opinions expressed by authors contributing to this journal do not necessarily reflect the opinions of the U.S. Department of Health and Human Services, the Public Health Service, the Centers for Disease Control and Prevention, or the authors' affiliated institutions. 
Table 3. Association Between Sleep Duration Categories and Ideal CVH in Sequential Adjusted Logistic and Linear Regression Models Among US Adults Aged 20-75 ( $=7,784)$, National Health and Nutrition Examination Survey, 2013-2016

\begin{tabular}{|c|c|c|c|c|}
\hline Sleep Duration, No. of Hours & Model $1^{a}$ Estimate $(95 \% \mathrm{Cl})$ & Model $2^{\text {b }}$ Estimate $(95 \% \mathrm{Cl})$ & Model $3^{\mathrm{C}}$ Estimate $(95 \% \mathrm{Cl})$ & Model $4^{\mathrm{d}}$ Estimate $(95 \% \mathrm{Cl})$ \\
\hline \multicolumn{5}{|l|}{ Odds of ideal CVH } \\
\hline$<6$ & 0.53 (0.39 to 0.72$)$ & $0.63(0.45$ to 0.87$)$ & $0.56(0.41$ to 0.77$)$ & 0.65 (0.47 to 0.90$)$ \\
\hline 6 to $<7$ & $0.90(0.76$ to 1.07$)$ & $0.97(0.80$ to 1.18$)$ & 0.91 (0.76 to 1.09$)$ & $0.97(0.80$ to 1.19$)$ \\
\hline 7 to $<8$ & & & & 1 [Reference] \\
\hline 8 to $<9$ & $1.03(0.82$ to 1.28$)$ & $0.95(0.74$ to 1.23$)$ & $1.04(0.84$ to 1.30$)$ & $0.96(0.75$ to 1.23$)$ \\
\hline$\geq 9$ & 0.75 (0.58 to 0.98$)$ & $0.70(0.53$ to 0.93$)$ & $0.78(0.60$ to 1.02$)$ & $0.72(0.55$ to 0.94$)$ \\
\hline \multicolumn{5}{|c|}{ Mean differences in CVH score, mean } \\
\hline$<6$ & $-0.80(-1.04$ to -0.55$)$ & $-0.48(-0.69$ to -0.27$)$ & $-0.69(-0.94$ to -0.45$)$ & $-0.41(-0.61$ to -0.20$)$ \\
\hline 6 to $<7$ & $-0.31(-0.45$ to -0.17$)$ & $-0.21(-0.34$ to -0.08$)$ & $-0.3(-0.44$ to -0.16$)$ & $-0.2(-0.33$ to -0.06$)$ \\
\hline 7 to $<8$ & & & & [Reference] \\
\hline 8 to $<9$ & $-0.15(-0.36$ to 0.06$)$ & $-0.18(-0.39$ to 0.03$)$ & $-0.12(-0.32$ to 0.07$)$ & $-0.16(-0.36$ to 0.03$)$ \\
\hline$\geq 9$ & $-0.51(-0.78$ to -0.24$)$ & $-0.38(-0.63$ to -0.13$)$ & $-0.45(-0.70$ to -0.19$)$ & $-0.33(-0.57$ to -0.09$)$ \\
\hline
\end{tabular}

Abbreviations: $\mathrm{Cl}$, confidence interval; $\mathrm{CVH}$, cardiovascular health; $\mathrm{OR}$, odds ratio.

a Model 1: Unadjusted.

${ }^{\mathrm{b}}$ Model 2: Adjusted for demographic factors of weighted age quartiles, sex, race/ethnicity, education level, and family income-to-poverty ratio category.

${ }^{\mathrm{c}}$ Model 3: Adjusted for social and clinical factors of depression status, binge alcohol use, and prescription sleep aid use.

${ }^{\mathrm{d}}$ Model 4: Fully adjusted model including factors from Models 2 and 3. 